\title{
Plasmablastic lymphoma versus diffuse large B cell lymphoma with plasmablastic differentiation: proposal for a novel diagnostic scoring system
}

\author{
Sonja Boy • Marlene van Heerden • Roger Pool • \\ Pascale Willem • Tomas Slavik
}

Received: 26 August 2014 / Accepted: 17 December 2014 / Published online: 15 January 2015

(C) Springer-Verlag Berlin Heidelberg 2015

\begin{abstract}
High-grade non-Hodgkin's lymphomas with plasmablastic differentiation are frequently encountered in HIV-positive patients. Differentiating between diffuse large B cell lymphoma (DLBCL) with plasmablastic differentiation and true cases of plasmablastic lymphoma (PBL) is sometimes challenging, particularly as a substantial overlap in immunphenotype exists between late-stage B cell neoplasms and PBL. This study sought to develop an immunohistochemical panel to more reliably distinguishing between PBL and DLBCL with plasmablastic differentiation. Thirty-nine CD20negative, ALK-negative, HHV8-negative non-Hodgkin's lymphomas with plasmablastic differentiation defined by their morphological features, high proliferation index and positivity for MUM1/IRF4 and PRDM/Blimp1 protein expression were compared regarding their protein expression profiles, viral status and c-MYC-gene aberrations. These lymphomas were subsequently
\end{abstract}

\footnotetext{
S. Boy $(\bowtie)$

Department of Pathology, Sefako Makgatho Health Sciences

University, Medunsa, Pretoria, South Africa

e-mail: sonja.iaop@gmail.com
}

M. van Heerden

Department of Oral Pathology and Oral Biology, Faculty of Health

Sciences University of Pretoria, Pretoria, South Africa

R. Pool

Department of Haematology, Faculty of Health Sciences, University of Pretoria, National Health Laboratory Services, Pretoria,

South Africa

P. Willem

Department of Molecular Medicine and Haematology, Faculty of Health Sciences, University of the Witwatersrand, National Health Laboratory Services, Johannesburg, South Africa

T. Slavik

Ampath Pathology Laboratories and Department of Anatomical

Pathology, University of Pretoria, Pretoria, South Africa divided in two groups utilising CD10 and Pax5. Tumours without reactivity for either of these markers exhibited higher expression of CD138 and CD117 frequently used as the plasma cell (PC) markers, whilst tumours with reactivity for one or both markers showed a significantly higher expression of CD38 and MYC-gene aberrations. A novel diagnostic scoring system which includes the immunohistochemical expression of CD10 and Pax 5 is proposed to differentiate between DLBCL with plasmablastic differentiation and true cases of PBL.

Keywords Plasmablastic lymphoma · Diffuse large B cell lymphoma $\cdot$ Plasmablastic differentiation $\cdot$ Diagnostic scoring $\cdot$ HIV

\section{Introduction}

B cell non-Hodgkin's lymphomas (NHLs) associated with HIV-infection share certain clinical and pathological features. The tendency to exhibit plasmablastic differentiation is perhaps one of the most peculiar microscopic phenomena exhibited by these neoplasms. The entity of plasmablastic lymphoma (PBL) was described as a highly aggressive neoplasm affecting the oral cavity of HIV-infected individuals [9, 16, 21,22]. Although previously classified as a sub-type of diffuse large B cell lymphoma (DLBCL), PBL is currently recognised as a distinct entity and acknowledged to infrequently also occur outside the oral cavity and in the absence of HIV infection [44]. Transition of a B lymphocyte through the plasmablastic differentiation stage to become a mature plasma cell (PC) is a complex process characterised by loss of B cell antigens and acquisition of $\mathrm{PC}$ differentiation markers. PBL is considered the prototype of large B cell NHL with plasmablastic differentiation present throughout the neoplastic proliferation. The distinction of DLBCL with significant 
plasmablastic differentiation from cases of true PBL, however, remains problematic in many cases. The relative lack of specific diagnostic criteria has contributed to a significant overlap and sometimes even confusion between these lymphoma entities in the literature. As patients diagnosed with PBL appear to have a significantly poorer overall survival than patients with DLBCL [40], reproducible distinction between these tumours is important from a prognostic point of view.

Owing to the high prevalence of HIV-infection, high-grade lymphomas with plasmablastic differentiation are encountered frequently amongst patients in South Africa [3, 4]. It was therefore decided to perform a 5-year retrospective analysis of oral cavity NHL diagnosed as PBL. The aim was to develop a diagnostic algorithm to more accurately distinguish true PBL from CD20-negative DLBCL with plasmablastic differentiation.

\section{Materials and methods}

\section{Inclusion criteria}

All CD20-negative, ALK-negative, HHV8-negative NHLs demonstrating typical morphological features of plasmablastic differentiation as defined by the WHO [44], immunoreactivity for MUM1/IRF4 and PRDM1/Blimp1 protein and with a high proliferation index on Ki67 staining were retrieved from the archives of the Department of Oral Pathology and Oral Biology, University of Pretoria, South Africa. Permission for this work was granted by the main Ethics Committee of the Faculty of Health Science (96/2011).

\section{Immunohistochemistry}

All retrieved cases were subjected to a battery of immunohistochemical markers (Table 1), which included additional B cell markers such as CD10, CD19, CD79a, bc16, and Pax5. Three micron sections from formalin-fixed paraffin wax embedded (FFPE) tissue blocks were dewaxed and hydrated to distilled water. Heat-induced epitope retrieval using a Pascal pressure chamber (Dako Cytomation, USA) was performed on the sections buffered at $\mathrm{pH} 6$ (citric acid) or $\mathrm{pH} 9$ (EDTA or TRIS/EDTA) depending on the specific antigen. Sections were treated with hydrogen peroxide to quench endogenous peroxidase activity and then incubated with their respective anti-sera. The antibodies were detected with either Envision+ System-HRP Labelled Polymer (Dako, Glostrup, Denmark) or Novolink Polymer Detection Kit (Novocastra, Leica Biosystems, UK) according to the manufacturer's recommendations and visualised with diaminobenzidine (DAB) chromogen (Dako, Glostrup, Denmark). Sections were counterstained with haematoxylin, and simultaneous positive and negative controls were performed in all cases. Brown granular staining of cell membranes (CD3, CD10, CD19, CD20, CD38, CD45, CD56, CD79a, CD138 and CD117), cytoplasm (ALK) or nuclei (Pax5, Ki67, bcl6, MUM, ALK, Blimp and HHV8) was regarded as positive when $20 \%$ or more of tumour cells showed signalling. Intensity of positive staining was noted as weak or strong. All analyses were undertaken in non-necrotic tumour areas by two independent observers.

In situ hybridisation

In situ hybridisation was performed on 3- $\mu$ m FFPE tissue block sections using EBV-encoded small nuclear RNA (EBER1/2) probes (Novocastra, Leica Biosystem, UK) for EBV, nuclear RNA probes (Novocastra, Leica Biosystem, UK) for HHV8 and INFORM ${ }^{\circledR}$ cytoplasmic lambda mRNA and kappa probe for kappa and lambda (Ventana Medical Systems, USA). The sections were dewaxed and hydrated to distilled water and digested with Proteinase K solution (Dako, Glostrup, Denmark) for 3-6 min at room temperature. Twenty microlitres of appropriate fluorescein-labelled EBV, HHV8, kappa and lambda probe were added to the different slides, cover slipped, denatured at $65^{\circ} \mathrm{C}$ for $15 \mathrm{~min}$ and hybridised at $37{ }^{\circ} \mathrm{C}$ for $2 \mathrm{~h}$. The hybridised EBV and HHV8 probes were detected using a universal ISH detection kit (Novocastra, Leica Biosystems, UK) according to the manufacturer's guidelines. The detection of kappa and lambda probes was performed using the ISH iVIEW Blue Detection kit (Ventana Medical Systems, USA) according to the manufacturer's guidelines. Sections were counterstained with haematoxylin and mounted with Faramount Aqueous Mounting Media (Dako, Glostrup, Denmark). Appropriate positive and negative controls were performed in all cases. Nuclear staining was regarded positive for EBV and HHV8, whilst cytoplasmic and/or membranous staining was regarded as positive for kappa/lambda light chains. Light chain restriction was defined as positivity for either kappa or lambda but no reactivity for the other.

Fluorescent in situ hybridisation

Cases were screened for breaks in the $M Y C$ gene using Vysis LSI dual-colour break apart (BA) rearrangement probes (Abbott Molecular Inc, IL, USA) and for MYC/IGH translocations using Vysis LSI IgH/Myc:CEP 8 tri-colour translocation probes. Four-micron sections were deparaffinised, rinsed in absolute alcohol and air-dried. After pre-treatment and digestion, $10 \mu \mathrm{L}$ of probe mixture $(7 \mu \mathrm{L}$ buffer solution, $2 \mu \mathrm{L}$ distilled water, $1 \mu \mathrm{L}$ probe) were applied to the slides. Denaturation and overnight hybridisation was performed in a thermocycler (Thermobrite, Abbot Molecular Illinois, USA) followed by a post hybridisation wash and counterstaining in $200 \mathrm{ng} / \mathrm{mL}$ 4',6-diamidino-2-phenylindole dihydrochloride (DAPI) (Merck, Darmstadt, Germany) on the sections, cover 
Table 1 Summary of antibodies and in situ hybridisation probes utilised in this study

\begin{tabular}{|c|c|c|c|c|c|}
\hline & Clone & Supplier & Dilution & HIER & Detection system \\
\hline \multicolumn{6}{|c|}{ Antibody (IHC) } \\
\hline CD20cy & L26 & DAKO Glostrup Denmark & RTU & Citric pH6 & Dako \\
\hline ALK & ALK1 & DAKO Glostrup Denmark & RTU & TRIS/EDTA pH9 & Dako \\
\hline CD45 & $2 \mathrm{~B} 11+\mathrm{PD} / 26$ & DAKO Glostrup Denmark & RTU & Citric pH6 & Dako \\
\hline CD3 & PS1 & Novocastra Leica Biosystems, UK & RTU & EDTA pH9 & Dako \\
\hline MUM1 & MUM1p & DAKO Glostrup Denmark & RTU & TRIS/EDTA pH9 & Dako \\
\hline Blimp-1 & 3H2-E8 & Novus Biologicals, Littleton, CO USA & $1: 200$ & TRIS/EDTA pH9 & Novocastra \\
\hline Ki67 & MM1 & Novocastra Leica Biosystems, UK & RTU & TRIS/EDTA pH9 & Dako \\
\hline $\mathrm{BCl} 6$ & PG-B6p & DAKO Glostrup Denmark & RTU & TRIS/EDTA pH9 & Novocastra \\
\hline CD10 & $56 \mathrm{C} 6$ & DAKO Glostrup Denmark & RTU & TRIS/EDTA pH9 & Dako \\
\hline CD19 & LE-CD19 & DAKO, Glostrup Denmark & RTU & Tris/EDTA pH9 & Novocastra \\
\hline CD79a & JCB117 & DAKO Glostrup Denmark & RTU & Citric pH6 & Dako \\
\hline $\operatorname{Pax} 5$ & DAK-Pax 5 & DAKO Glostrup Denmark & RTU & Tris/EDTA pH9 & Novocastra \\
\hline CD38 & SPC32 & Novocastra Leica Biosystems UK & $1: 100$ & Citric pH6 & Dako \\
\hline CD138 & MI15 & DAKO Glostrup Denmark & $1: 50$ & Citric pH6 & Dako \\
\hline CD56 & $123 \mathrm{C} 3$ & DAKO Glostrup Denmark & RTU & TRIS/EDTA pH9 & Dako \\
\hline CD117 & polyclonal & DAKO Glostrup Denmark & $1: 400$ & EDTA pH9 & Novocastra \\
\hline \multicolumn{6}{|l|}{ Probe (ISH) } \\
\hline HHV8 & mRNA & Novocastra Leica Biosystems, UK & RTU & Proteinase $\mathrm{K}$ & Novocastra \\
\hline EBER & mRNA nuclear & Novocastra Leica Biosystems, UK & RTU & Proteinase $\mathrm{K}$ & Novocastra \\
\hline Kappa & mRNA cytoplasmic & Ventana Medical Systems, Inc. Tucson, AZ, USA & RTU & Proteinase $\mathrm{K}$ & Ventana \\
\hline Lambda & mRNA cytoplasmic & Ventana Medical Systems, Inc. Tucson, AZ, USA & RTU & Proteinase K & Ventana \\
\hline
\end{tabular}

HIER heat-induced epitope retrieval, IHC immunohistochemistry, ISH in situ hybridisation, $R T U$ ready to use

slipping with Vectashield fluorescence mounting media (Vector Laboratories Inc, Burlingame, CA, USA) and evaluation with a Nikon Eclipse E1000 microscope equipped with a spectrum-green, orange, aqua, DAPI and triple band filter. Slides were scored after counting at least 100 nuclei. Cut-off values for the FISH analysis were $5 \%$ for the BA probe and $15 \%$ for the fusion probe.

\section{Results}

A total of 39 NHL cases conformed to the inclusion criteria. Twenty-three cases were confirmed as HIV positive and 16 were strongly suspected to be HIV positive on clinical findings. CD19, CD79a and bcl6 were not regarded as specific enough to reliably discriminate B cells from plasmablasts and PCs (see later). Cases were subdivided into two groups according to their staining for the additional B cell markers CD10 and Pax5. Statistical analysis was done using the Fisher exact test. Immunohistochemical characterisation of the lymphomas is summarised in Table 2. Group $1(n=23)$ consisted of cases negative for both $\mathrm{CD} 10$ and Pax5, and group 2 $(n=16)$ consisted of cases positive for CD10 and/or Pax5. Only four of the 16 cases $(25 \%)$ in group 2 were positive for both CD10 and Pax5, seven cases (44\%) were positive for only CD10 and five cases $(31 \%)$ were only Pax5 positive without CD10 reactivity. All cases showed a high Ki67 proliferation fraction (bordering on $100 \%$ in some cases). No correlation could be found between morphology and the expression of additional B lineage markers. The presence of morphologically mature PCs varied but always constituted less than $1 \%$ of the tumour cell population. CD38 expression was significantly higher in lymphomas of group $2(p=0.006)$, whilst CD138 $(p=0.006)$ and CD117 $(p<0.001)$ expression was significantly higher in group 1 . Interestingly, group 2 lymphomas also showed a much higher incidence of $M Y C$ gene breaks $(p=0.006)$ and $t(8 ; 14)$ rearrangements $(p<0.001)$, than group 1 . There were no statistically significant differences in the expression of LCA $(p=0.469), \operatorname{bcl} 6(p=0.303)$, CD79a $(p=0.363)$, CD56 ( $p=0.522)$, kappa and lambda light chain restriction $(p=0.075)$ or $\operatorname{EBV} \operatorname{EBER}(p=0.604)$ between the two groups.

\section{Discussion}

NHLs are AIDS-defining neoplasms diagnosed with a high frequency in South Africa [3, 4]. The vast majority of HIVrelated NHLs are aggressive, high-grade B lineage 
Table 2 Comparison between cases with and without reactivity for Pax 5 and $\mathrm{CD} 10$ as additional $\mathrm{B}$ cell markers

\begin{tabular}{|c|c|c|c|}
\hline & $\begin{array}{l}\text { Group } 1 \\
\text { Negative for } \\
\text { additional B-cell } \\
\text { markers }(n=23)\end{array}$ & $\begin{array}{l}\text { Group } 2 \\
\text { Positive for } \\
\text { additional B-cell } \\
\text { markers }(n=16)\end{array}$ & $\begin{array}{l}\text { Fisher } \\
\text { exact }\end{array}$ \\
\hline $\mathrm{CD} 20$ & None & None & \\
\hline CD45 & $13(57 \%)$ & $8(50 \%)$ & $p=0.469$ \\
\hline CD3 & None & $1(6 \%)$ & \\
\hline MUM1 & $23(100 \%)$ & $16(100 \%)$ & \\
\hline Blimp1 & $23(100 \%)$ & $16(100 \%)$ & \\
\hline BCL6 & $7(30 \%)$ & $7(44 \%)$ & $p=0.303$ \\
\hline CD10 & None & $11(69 \%)$ & \\
\hline CD19 & None & $2(13 \%)$ & \\
\hline CD79a & $1(4 \%)$ & $2(13 \%)$ & $p=0.363$ \\
\hline Pax 5 & None & $9(56 \%)$ & \\
\hline CD38 & $10(43 \%)$ & $14(88 \%)$ & $p=0.006$ \\
\hline CD138 & $20(87 \%)$ & $7(44 \%)$ & $p=0.006$ \\
\hline CD56 & $4(17 \%)$ & $2(13 \%)$ & $P=0.522$ \\
\hline CD117 & $2(9 \%)$ & None & \\
\hline EBER & 19/21 (90 \%) & 15/16 (94 \%) & $p=0.604$ \\
\hline HHV8 & None & None & \\
\hline Light chain restriction & $16 / 22(73 \%)$ & 6/14 (43\%) & $p=0.075$ \\
\hline MYC BA & $7 / 20(35 \%)$ & $11 / 13(85 \%)$ & $p=0.006$ \\
\hline$t(8 ; 14)$ & $3 / 17(18 \%)$ & $9 / 10(90 \%)$ & $p<0.001$ \\
\hline
\end{tabular}

lymphomas that demonstrate morphologic and immunophenotypic features suggestive of plasmablastic differentiation in only some of the tumour cells or diffusely throughout the neoplastic proliferation. Plasmablastic differentiation is loosely defined on the basis of the acquisition of morphological and immunophenotypic features portraying cellular commitment to the PC programme. Morphologically, plasmablasts are either large immunoblast-like cells with prominent central nucleolus in an eccentrically located nucleus or have multiple nucleoli in a slightly irregularly shaped nucleus. A combination of these morphological patterns is common. Immunophenotypically, plasmablasts are cells which have lost their B cell phenotype, acquired the transcriptional and antigenic profile of PCs and usually also demonstrate a high proliferation rate $[5,16,43,45]$. Combinations of $\mathrm{B}$ cell and PC markers are therefore employed to define plasmablastic differentiation within a B lineage lymphoma. The presence of PRDM1/Blimp1, MUM1/IRF4 [28], and especially combined expression thereof are reliable indicators of this pathway of cellular differentiation.

According to the 2008 WHO Classification, PBL is no longer considered a subtype of DLBCL [45] but the differentiation between PBL and DLBCL, particularly if plasmablastic differentiation is present, remains problematic. Simplistically viewed, terminal differentiation of the B cell to a PC necessitates shutdown of the $\mathrm{B}$ differentiation programme reflected by a loss of $\mathrm{B}$ cell markers and expression of PC differentiation markers such as CD38, CD138, CD56 and CD117. In reality, however, B cell to PC differentiation includes a less characterised transient phase represented by the plasmablast. The transient nature of a plasmablast, as reflected by its changing gene and protein expression, has prompted some investigators to sub-classify this phase into preplasmablast and plasmablast stages [27, 34, 47]. Progression between the different maturation stages is a gradual process with potential phenotypic overlaps between the late $\mathrm{B}$ cell and the early or pre-plasmablast as well as between the late or mature plasmablast and PC stages of development (Fig. 1). The exact antigen expression profile of neoplastic plasmablasts has also not been fully characterised and what is accepted to be in keeping with a diagnosis PBL varies amongst authors (Fig. 2). This may seem purely academic but unravelling these differences may become increasingly relevant in the era of targeted therapy.

Both the pre-plasmablast and plasmablast stages of B cell maturation were recently demonstrated to have complete absence of B cell antigen expression during normal maturation [27] (Fig. 2). Controversy however exists regarding the immunophenotype of neoplastic lymphocytes in this post-B cell phase of maturation. Weak expression of $\mathrm{B}$ cell markers by neoplastic plasmablasts in PBL is accepted by some authors [34, 41, 50] (Fig. 2), but this weak degree of positivity is not defined or quantified in these studies. This has thus introduced a significant degree of diagnostic confusion with respect to typing a neoplastic lymphoid proliferation as either a true case of PBL or DLBC with plasmablastic differentiation.

CD20 is one of the oldest and most commonly used B cell markers utilised in immunohistochemistry, but loss of CD20 does not exclude a B lineage and a more extensive antibody panel is required to confirm an apparent non-B cell lineage [12]. The panel of additional B cell markers in this study consisted of bcl6, CD79a, CD19, Pax5, and CD10. BCL6 is acknowledged as a transcriptional repressor governing germinal centre (GC) formation $[28,52]$ but it is still unknown at which point in $\mathrm{B}$ cell maturation its upregulation occurs. Although downregulation of $B C L 6$ expression is necessary to complete the process of terminal differentiation to mature PCs, its presence does not inhibit initiation of PC differentiation [17] and a certain degree of remnant bcl6 positivity may therefore potentially be encountered in post-GC B cell neoplasms such as PBL. CD79a is a diagnostically sensitive pan$\mathrm{B}$ cell marker expressed from the pro-B cell stage through to the PC stage. [32] The JCB117 clone utilised in this study was previously proven to exhibit the greatest degree of $\mathrm{B}$ cell lineage fidelity [32]. Interestingly, CD79a reactivity was seen in only three cases in this study consistent with results from previous studies $[25,50]$. CD19, a transmembrane glycoprotein in the immunoglobulin superfamily [10] is regarded as 
Fig. 1 The dotted circles in the diagram demonstrate the two phases in B cell maturation where potential phenotypic overlap in the expression of $\mathrm{B}$ cell and $\mathrm{PC}$ antigens may occur $(B \mathrm{~B}$ cell, $P B$ plasmablast, $P C$ plasma cell)

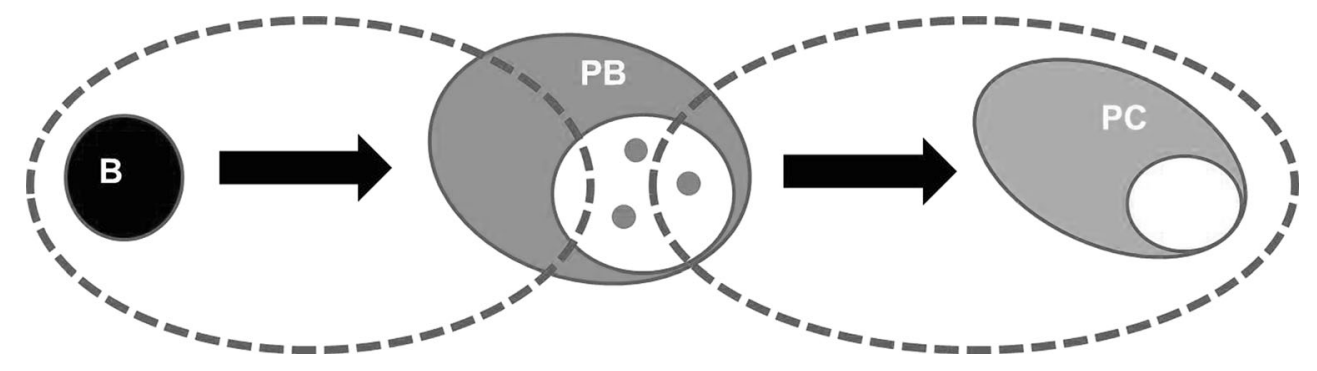

one of the most reliable surface biomarkers for B cells [51] and is expressed approximately at the time of immunoglobulin rearrangement through terminal differentiation to PCs $[15$, 51]. Interestingly, as with CD79a, CD19 reactivity was seen in only two cases, both of which also showed Pax5 positivity. The reasons why CD79a and CD19 are not expressed more often by these tumours of obvious B lineage is unknown and has not been addressed before. As with bcl6, the possibility of extended expression of both CD79a and CD19 into the post$\mathrm{GC} /$ plasmablastic phases of B-cell differentiation warranted their exclusion as potential discriminating $\mathrm{B}$ cell markers in the quest to distinguish late-stage $\mathrm{B}$ cells from plasmablasts.

The two most promising additional $\mathrm{B}$ cell markers utilised for this study were Pax5 and CD10. Pax5 is a B cell-specific activator protein whose expression is largely limited to cells with B lymphoid lineage commitment. [38] It is regarded as a reliable $\mathrm{B}$ cell differentiation antigen before the cells acquire plasmacytic features. [12] Nine cases in this study showed weak to strong Pax 5 positivity in most of the tumour cell nuclei. These cases all had clear and diffuse plasmablastic differentiation as defined by morphological features, a high proliferation index and strong, diffuse PRDM1/Blimp1 and
IRF4/MUM1 expression (Fig. 3). Whilst exceedingly rare, cases of PC myeloma showing aberrant Pax 5 expression have been reported although these have usually also been CD20 positive [29]. Nonetheless, Pax5 expression remains a confirmatory marker of a B cell rather than plasmablastic or PC phenotype. CD10, a cell surface metallopeptidase is expressed on early lymphoid progenitors and a small subset of immature bone marrow B cells. CD10 expression is lost as the cells reach maturation and is re-expressed on proliferating $\mathrm{B}$ cells in which setting it is generally regarded as an early germinal centre (GC) B cell marker [7, 18]. CD10 is also useful in the diagnostic armamentarium for Burkitt lymphoma. [37, 45] Twenty to $40 \%$ of DLBCL cases express CD10 [11] and are thereby recognised to have a clinically more favourable GC phenotype in risk-stratification algorithms $[1,24,36]$. In this study, six of the CD10-positive cases showed strong and diffuse membranous positivity in more than $80 \%$ of the tumour cells, whilst five cases showed weaker expression in $20-50 \%$ of their cells. Few studies relating to PBL have included Pax 5 and/or CD10 staining in their immunohistochemical panels, but positivity for both markers has been reported in cases published as PBL $[13,14,18,50]$. Although

Fig. 2 The diagram represents a summary of the antigen expression profiles of the preplasmablast (pre- $P B)$ and plasmablast $(P B)$ during maturation of a normal $\mathrm{B}$ cell as described by Jourdan et al [27]. As indicated by the two red circles, weak B cell antigen expression by abnormal/ neoplastic plasmablasts is however accepted by some authors, causing diagnostic confusion when trying to differentiate between DLBCL with plasmablastic differentiation and true cases of PBL

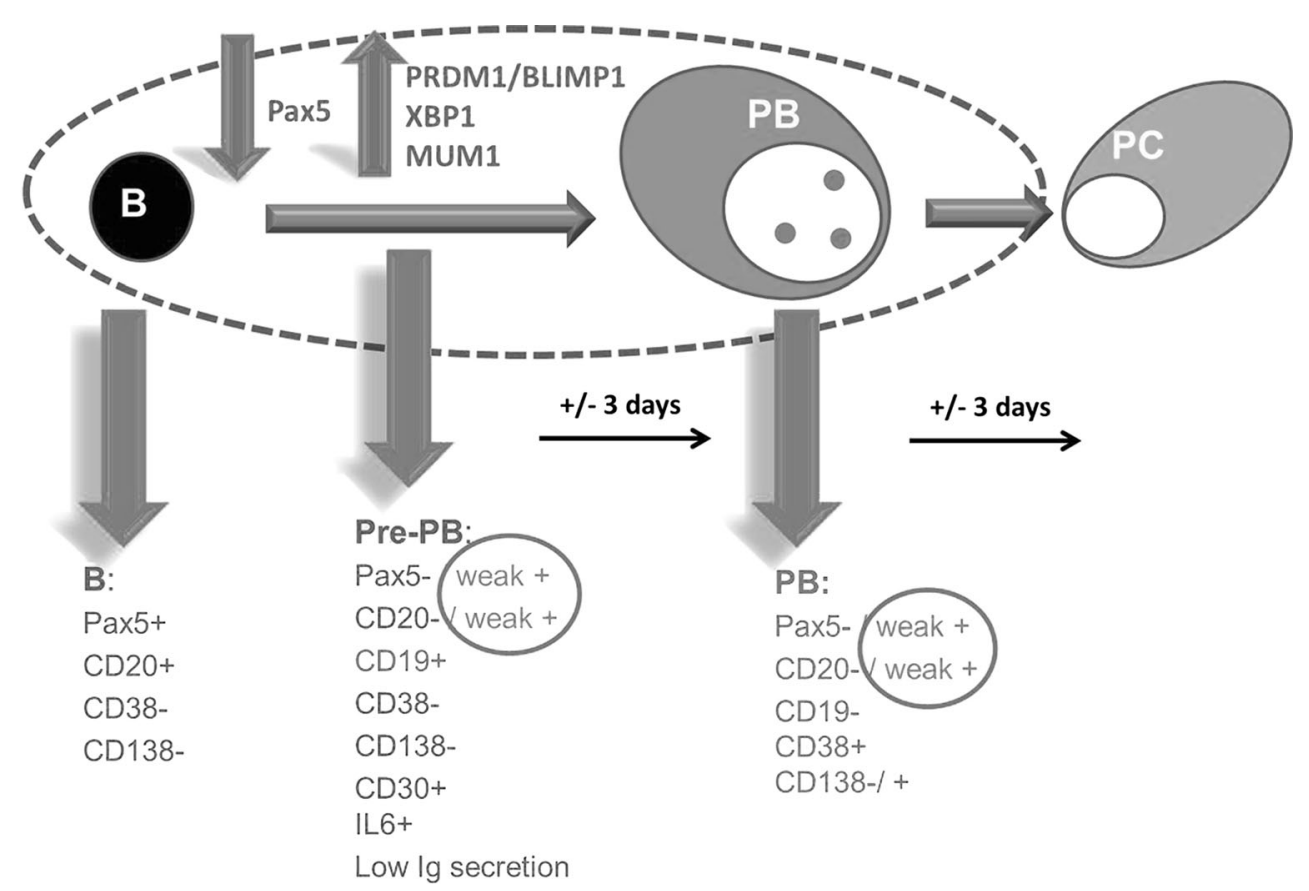


Fig. 3 These photomicrographs show a case with expression of the additional $\mathrm{B}$ cell markers in addition to MUM1/IRF4 and PRDM1/Blimp1 expression. a Diffuse Pax5 expression (score $0)$; b strong and diffuse MUM1/IRF4 and c PRDM1/ Blimp1 stains of the same case. d An example of weak Pax 5 expression (score 1). e An example of diffuse CD10 expression (score 0 )
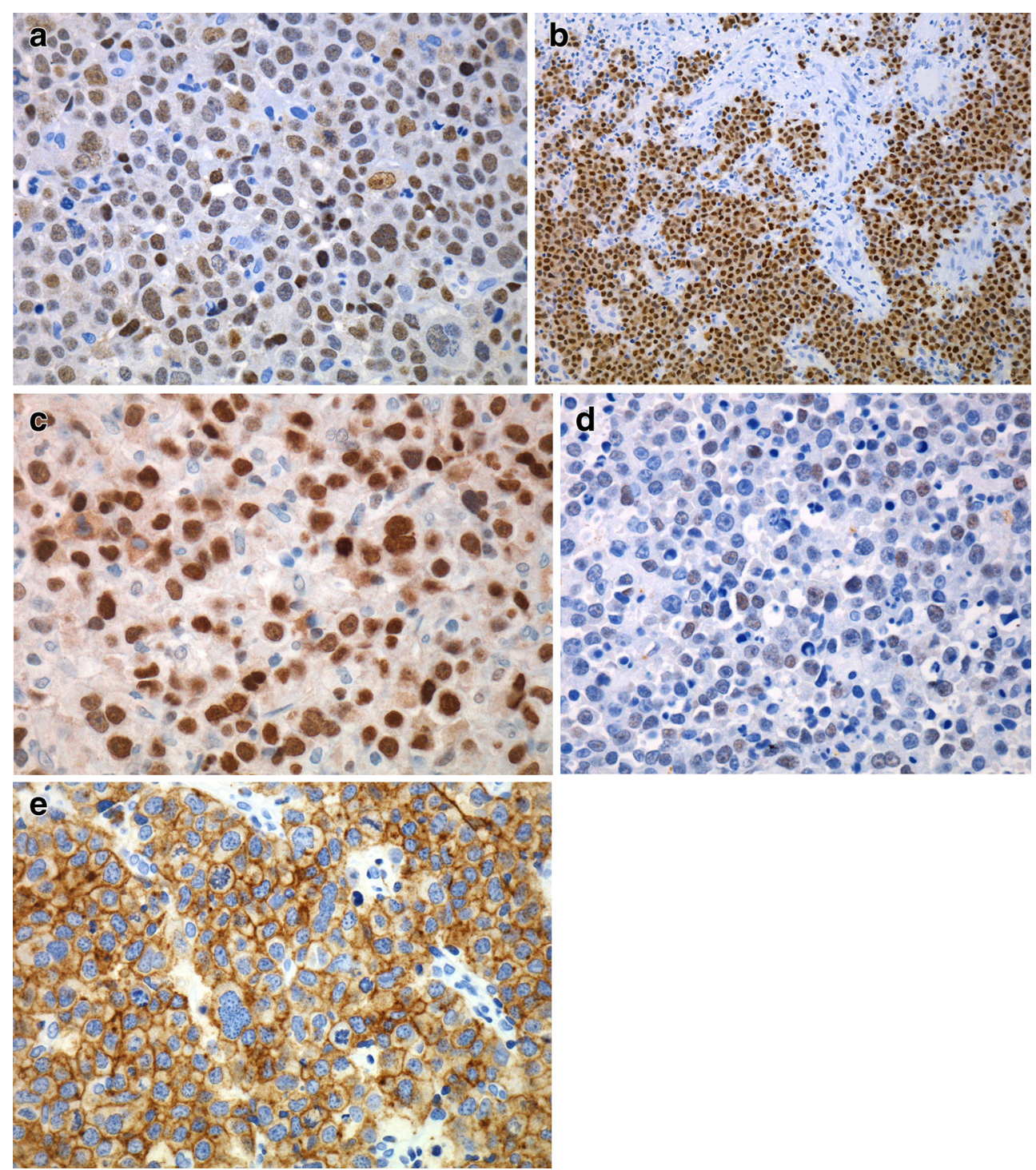

aberrant protein expression is possible and well recognised in neoplastic cells, the overt expression of early B cell markers such as Pax 5 and CD10 (and especially both) in a neoplasm classified as plasmablastic lymphoma should be interpreted with great caution.

The use of PC differentiation markers in the diagnostic algorithm of PBL was also considered. The expression of CD38 and CD138 in our study population varied from completely negative to strongly and diffusely positive in $100 \%$ of the tumour cells. CD38, a transmembrane glycoprotein is expressed on lymphoid as well as myeloid cells and used in the diagnostic armamentaria of PC myeloma [30] and Burkitt lymphoma [37]. In this study, CD38 was expressed significantly more often $(p=0.006)$ in the group which showed additional B cell marker expression. The reason for this in uncertain but since $\mathrm{CD} 38$ positivity can be encountered in $\mathrm{B}$ cell and $\mathrm{PC}$ neoplasms, it was decided not to utilise this stain as a possible discriminator between B cell and PC stages of development. CD138 is accepted as a universal marker of normal and malignant PCs [2] and was expressed significantly more commonly $(p=0.006)$ in the B cell marker-negative group. The expression ratio of $\mathrm{CD} 38$ versus $\mathrm{CD} 138$ is also applied in the characterisation of the various stages of plasmablastic differentiation. [27, 34] In their flow cytometric study on normal plasmablast development, Jourdan et al. showed pre-plasmablasts to be CD20-, CD19+, CD38- and CD138-, plasmablasts to be CD20-, CD19+, CD38 $8^{\mathrm{High}}$ and CD138- and late plasmablasts/PCs to be CD20-, CD19-, $\mathrm{CD} 38^{\mathrm{High}}$ and $\mathrm{CD} 138^{\mathrm{High}}$ [27]. CD138, in contrast to CD38 which as alluded to before is regularly encountered in $\mathrm{B}$ cell neoplasms, seems to be more consistently associated with an advanced plasmablast or PC phenotype and was thus included in our diagnostic scoring system for PBL.

Other markers frequently used in the diagnostic armamentarium of PC neoplasms that were also applied in our study were CD56 and CD117. Both CD56 [33, 49, 19, 20, 42] and 
Fig. 4 The diagram represents the summary of the proposed diagnostic scoring system to distinguish true cases of PBL from those high-grade NHLs which should rather be diagnosed as DLBCL with plasmablastic differentiation. Interpretation of scoring: 7-8, consistent with a true case of PBL; 5-6, PBL is not excluded. Supplemental Ki-67 and EBER testing recommended. A proliferation index of $>90 \%$ should add 1 point, and the presence of EBV another. If the score still remains $<7$, diagnose DLBCL with plasmablastic differentiation. If 7 or more, diagnose PBL. $<5$, DLBCL with plasmablastic differentiation
CD20-, Blimp1-positive, MUM1-positive lymphoid neoplasm

- Morphology (0 - cellular morphology not characteristic; 2 cellular morphology characteristic of plasmablastic differentiation as defined by the WHO)

- Pax5 (0-positive; 1 - weak/ focal; 2 - negative)

- CD10 (0-positive; 1 - weak/ focal; 2 - negative)

- CD138 (0 - negative; 1 - weak/ focal; 2- positive)

\section{Cumulative Score}

7-8:PBL

5-6 : If Ki67>90\% and EBV is positive - add 1 for each

$<5$ : DLBCL with plasmablastic differentiation

CD117 [2, 31, 39] are reported to be expressed by neoplastic PCs and CD56 is also positive in a small percentage of nonneoplastic PCs $[6,31]$. Its role in B cell maturation and expression on plasmablasts have, however, never been investigated and its utility to distinguish between B cells, plasmablasts and PCs is thus not known. Previous studies have reported CD56 expression to range from 5 to more than $50 \%$ in cases diagnosed as PBL $[14,26,50]$. Some ascribed this to aberrant expression in neoplastic plasmablasts [50] whilst others postulate it to be due to PBL arising secondary to dedifferentiation in a mature PC neoplasm [14]. Six cases $(17.9 \%)$ in this series showed CD56 reactivity in $40-100 \%$ of their cells (Table 2) although no significant difference was noted between the two defined groups. Only two cases showed weak and focal expression of CD117 (Table 2) and were expectantly also negative for all the $\mathrm{B}$ lineage markers. Due to the uncertainty regarding expression patterns in these cells, these markers were excluded from the scoring system.

An interesting finding in this study was the significantly higher $t(8 ; 14)$ found in the PAX5/CD10-positive group lymphomas. The presence of MYC rearrangements, and specifically Burkitt types of MYC rearrangements, are generally more common in B cell malignancies derived from early stage of B cell development such as GC-derived DLBCL [35]. This is likely to reflect such DLBCL cases presenting with plasmacytoid features, a particularity described in HIVassociated lymphomas [23].
In this study, $92 \%$ of all cases were positive for EBV EBER on in situ hybridisation. There is evidence that a pathogenic association may exist between EBV, HIV and a PC phenotype in B cell neoplasia. [8] Although EBV may be encountered in DLBCL with plasmablastic differentiation, this association is most striking in HIV-negative individuals. Thus, whilst EBV infection has been reported in 60 to $100 \%$ of lymphomas diagnosed as PBL in the literature [4, 46, 48], its presence seems to be most valuable when attempting to distinguish PBL from DLBCL outside the HIV setting.

The proliferation fraction of PBL is known to be extremely high and borders on $100 \%$ in many cases. Although EBVpositive DLBCLs may sometimes present with a proliferation fraction this high, a proliferation fraction of $<80 \%$ in a B cell lymphoma, especially in an HIV-negative patient, favours DLBCL over PBL. The proliferation fraction is therefore another useful (albeit less reliable) parameter in a PBL diagnostic scoring system such as this.

The current WHO categorisation of PBL as a distinct lymphoma entity and the recent evidence of a poorer outcome in PBL when compared to DLBCL make it imperative to differentiate true PBL from DLBCL with plasmablastic differentiation. No reliable criteria presently exist for reproducible distinction between these two lymphoma entities. Based on current knowledge and results from this study, we present a novel yet simple scoring system to distinguish true PBL from DLBCL with plasmablastic differentiation (Fig. 4). One of the strengths of the system is that it takes into consideration the 
known variability in protein expression which may occur in PBL. Whilst additional validation of the scoring system is required and future, more specific markers may further refine this scheme, it represents an attempt to improve current diagnostic reproducibility of PBL amongst histopathologists. This is needed if we are to gain further insight and understanding into the oncogenesis and molecular biology of these enigmatic lymphomas.

Acknowledgments The authors wish to thank Prof. Willie van Heerden, Head of the Department of Oral Pathology at the University of Pretoria, for providing the infrastructure, PBL samples from his department and some of the financial support for this study; Prof. Marco Allesandrini from the Department of Immunology and Institute for Cellular and Molecular Medicine for the statistical analysis; the National Health Laboratory Services (NHLS) for partial funding of this study; Diagnostech (Honeydew, South Africa) for their kind donation of the Dako CD19 serum utilised in this study and Professors Theuns Swart and Keith Hunter for proof reading the manuscript.

Author contributions Prof SC Boy designed the research study, performed research, analysed the data and wrote the paper. Mrs MB van Heerden performed the research, analysed the data and assisted in the preparation of the paper. Prof R Pool analysed the data and assisted in the preparation of the paper. Dr P Willem analysed the genetic data and assisted in the preparation of the paper. Dr T Slavik performed the research, analysed the data and wrote the paper.

Conflict of interest The authors declare no conflict of interest.

\section{References}

1. Amen F, Horncastle D, Elderfield K, Banham AH, Bower M, Macdonald D, Kanfer E, Naresh KN (2007) Absence of cyclin-D2 and Bcl-2 expression within the germinal centre type of diffuse large B-cell lymphoma identifies a very good prognostic subgroup of patients. Histopathology 51:70-79

2. Bataille R, Jego G, Robillard N, Barille-Nion S, Harousseau JL, Moreau P, Amiot M, Pellat-Deceunynck C (2006) The phenotype of normal, reactive and malignant plasma cells. Identification of "many and multiple myelomas" and of new targets for myeloma therapy. Haematologica 91:1234-1240

3. Boy SC, van Heerden MB, Babb C, van Heerden WF, Willem P (2011) Dominant genetic aberrations and coexistent EBV infection in HIV-related oral plasmablastic lymphomas. Oral Oncol 47:883-887

4. Boy SC, van Heerden MB, Raubenheimer EJ, van Heerden WF (2010) Plasmablastic lymphomas with light chain restrictionplasmablastic extramedullary plasmacytomas? J Oral Pathol Med 39:435-439

5. Campo E, Chott A, Kinney MC, Leoncini L, Meijer CJ, Papadimitriou CS, Piris MA, Stein H, Swerdlow SH (2006) Update on extranodal lymphomas. Conclusions of the Workshop held by the EAHP and the SH in Thessaloniki, Greece. Histopathology 48: 481-504

6. Cannizzo E, Bellio E, Sohani AR, Hasserjian RP, Ferry JA, Dorn ME, Sadowski C, Bucci JJ, Carulli G, Preffer F (2010) Multiparameter immunophenotyping by flow cytometry in multiple myeloma: the diagnostic utility of defining ranges of normal antigenic expression in comparison to histology Cytometry. Part B. Clin Cytom 78:231-238
7. Caraux A, Klein B, Paiva B, Bret C, Schmitz A, Fuhler GM, Bos NA, Johnsen HE, Orfao A, Perez-Andres M (2010) Circulating human B and plasma cells. Age-associated changes in counts and detailed characterization of circulating normal CD138- and CD138+ plasma cells. Haematologica 95:1016-1020

8. Carbone A, Cesarman E, Spina M, Gloghini A, Schulz TF (2009) HIV-associated lymphomas and gamma-herpesviruses. Blood 113: $1213-1224$

9. Carbone A, Gaidano G, Gloghini A, Ferlito A, Rinaldo A, Stein H (1999) AIDS-related plasmablastic lymphomas of the oral cavity and jaws: a diagnostic dilemma. Ann Otol Rhinol Laryngol 108:95-99

10. Carter RH, Barrington RA (2004) Signaling by the CD19/CD21 complex on B cells. Curr Dir Autoimmun 7:4-32

11. Chan ACL, Chan KC (2011) Diffuse large B-cell lymphoma. In: Jaffe E, Lee Harris N, Vardiman JW, Campo E, Arber DA (eds) Hematopathology. Elsevier Saunders, pp. 349-381

12. Chu PG, Loera S, Huang Q, Weiss LM (2006) Lineage determination of CD20- B-Cell neoplasms: an immunohistochemical study. Am J Clin Pathol 126:534-544

13. Chuah KL, Ng SB, Poon L, Yap WM (2009) Plasmablastic lymphoma affecting the lung and bone marrow with CD10 expression and $\mathrm{t}(8 ; 14)(\mathrm{q} 24 ; \mathrm{q} 32)$ translocation. Int J Surg Pathol 17:163-166

14. Colomo L, Loong F, Rives S, Pittaluga S, Martinez A, LopezGuillermo A, Ojanguren J, Romagosa V, Jaffe ES, Campo E (2004) Diffuse large B-cell lymphomas with plasmablastic differentiation represent a heterogeneous group of disease entities. Am J Surg Pathol 28:736-747

15. Craig FE, Foon KA (2008) Flow cytometric immunophenotyping for hematologic neoplasms. Blood 111:3941-3967

16. Delecluse HJ, Anagnostopoulos I, Dallenbach F, Hummel M, Marafioti T, Schneider U, Huhn D, Schmidt-Westhausen A, Reichart PA, Gross U, Stein H (1997) Plasmablastic lymphomas of the oral cavity: a new entity associated with the human immunodeficiency virus infection. Blood 89:1413-1420

17. Diehl SA, Schmidlin H, Nagasawa M, van Haren SD, Kwakkenbos MJ, Yasuda E, Beaumont T, Scheeren FA, Spits H (2008) STAT3mediated up-regulation of BLIMP1 is coordinated with BCL6 downregulation to control human plasma cell differentiation. J Immunol 180:4805-4815

18. Dogan A, Bagdi E, Munson P, Isaacson PG (2000) CD10 and BCL-6 expression in paraffin sections of normal lymphoid tissue and B-cell lymphomas. Am J Surg Pathol 24:846-852

19. Dunphy CH, Nies MK, Gabriel DA (2007) Correlation of plasma cell percentages by CD138 immunohistochemistry, cyclin D1 status, and CD56 expression with clinical parameters and overall survival in plasma cell myeloma. Appl Immunohistochem Mol Morphol 15: 248-254

20. Ely SA, Knowles DM (2002) Expression of CD56/neural cell adhesion molecule correlates with the presence of lytic bone lesions in multiple myeloma and distinguishes myeloma from monoclonal gammopathy of undetermined significance and lymphomas with plasmacytoid differentiation. Am J Pathol 160:1293-1299

21. Flaitz CM, Nichols CM, Walling DM, Hicks MJ (2002) Plasmablastic lymphoma: an HIV-associated entity with primary oral manifestations. Oral Oncol 38:96-102

22. Gaidano G, Cerri M, Capello D, Berra E, Deambrogi C, Rossi D, Larocca LM, Campo E, Gloghini A, Tirelli U, Carbone A (2002) Molecular histogenesis of plasmablastic lymphoma of the oral cavity. Br J Haematol 119:622-628

23. Gloghini A, Dolcetti R, Carbone A (2013) Lymphomas occurring specifically in HIV-infected patients: from pathogenesis to pathology. Semin Cancer Biol 23:457-467

24. Hans CP, Weisenburger DD, Greiner TC, Gascoyne RD, Delabie J, Ott G, Muller-Hermelink HK, Campo E, Braziel RM, Jaffe ES, Pan Z, Farinha P, Smith LM, Falini B, Banham AH, Rosenwald A, Staudt LM, Connors JM, Armitage JO, Chan WC (2004) Confirmation of 
the molecular classification of diffuse large B-cell lymphoma by immunohistochemistry using a tissue microarray. Blood 103: 275-282

25. Hansra D, Montague N, Stefanovic A, Akunyili I, Harzand A, Natkunam Y, de la Ossa M, Byrne GE, Lossos IS (2010) Oral and extraoral plasmablastic lymphoma: similarities and differences in clinicopathologic characteristics. Am J Clin Pathol 134:710-719

26. Hsi ED, Lorsbach RB, Fend F, Dogan A (2011) Plasmablastic lymphoma and related disorders. Am J Clin Pathol 136:183-194

27. Jourdan M, Caraux A, Caron G, Robert N, Fiol G, Reme T, Bollore K, Vendrell JP, Le Gallou S, Mourcin F, De Vos J, Kassambara A, Duperray C, Hose D, Fest T, Tarte K, Klein B (2011) Characterization of a transitional preplasmablast population in the process of human B cell to plasma cell differentiation. J Immunol 187:3931-3941

28. Klein U, Dalla-Favera R (2008) Germinal centres: role in B-cell physiology and malignancy. Nat Rev Immunol 8:22-33

29. Lin P, Mahdavy M, Zhan F, Zhang HZ, Katz RL, Shaughnessy JD (2004) Expression of PAX5 in CD20-positive multiple myeloma assessed by immunohistochemistry and oligonucleotide microarray. Mod Pathol 17:1217-1222

30. Lin P, Owens R, Tricot G, Wilson CS (2004) Flow cytometric immunophenotypic analysis of 306 cases of multiple myeloma. Am J Clin Pathol 121:482-488

31. Liu D, Lin P, Hu Y, Zhou Y, Tang G, Powers L, Medeiros LJ, Jorgensen JL, Wang SA (2012) Immunophenotypic heterogeneity of normal plasma cells: comparison with minimal residual plasma cell myeloma. J Clin Pathol 65:823-829

32. Mason DY, Cordell JL, Brown MH, Borst J, Jones M, Pulford K, Jaffe E, Ralfkiaer E, Dallenbach F, Stein H (1995) CD79a: a novel marker for B-cell neoplasms in routinely processed tissue samples. Blood 86:1453-1459

33. Mateo G, Castellanos M, Rasillo A, Gutierrez NC, Montalban MA, Martin ML, Hernandez JM, Lopez-Berges MC, Montejano L, Blade J, Mateos MV, Sureda A, de la Rubia J, Diaz-Mediavilla J, Pandiella A, Lahuerta JJ, Orfao A, San Miguel JF (2005) Genetic abnormalities and patterns of antigenic expression in multiple myeloma. Clin Cancer Res 11:3661-3667

34. Montes-Moreno S, Gonzalez-Medina AR, Rodriguez-Pinilla SM, Maestre L, Sanchez-Verde L, Roncador G, Mollejo M, Garcia JF, Menarguez J, Montalban C, Ruiz-Marcellan MC, Conde E, Piris MA (2010) Aggressive large B-cell lymphoma with plasma cell differentiation: immunohistochemical characterization of plasmablastic lymphoma and diffuse large B-cell lymphoma with partial plasmablastic phenotype. Haematologica 95:1342-1349

35. Morton LM, Kim CJ, Weiss LM, Bhatia K, Cockburn M, Hawes D, Wang SS, Chang C, Altekruse SF, Engels EA, Cozen W (2014) Molecular characteristics of diffuse large B-cell lymphoma in human immunodeficiency virus-infected and -uninfected patients in the prehighly active antiretroviral therapy and pre-rituximab era. Leuk Lymphoma 55:551-557

36. Muris JJ, Meijer CJ, Vos W, van Krieken JH, Jiwa NM, Ossenkoppele GJ, Oudejans JJ (2006) Immunohistochemical profiling based on Bcl-2, CD10 and MUM1 expression improves risk stratification in patients with primary nodal diffuse large B cell lymphoma. J Pathol 208:714-723

37. Naresh KN, Ibrahim HA, Lazzi S, Rince P, Onorati M, Ambrosio MR, Bilhou-Nabera C, Amen F, Reid A, Mawanda M, Calbi V, Ogwang M, Rogena E, Byakika B, Sayed S, Moshi E, Mwakigonja A, Raphael M, Magrath I, Leoncini L (2011) Diagnosis of Burkitt lymphoma using an algorithmic approach - applicable in both resource-poor and resource-rich countries. Br J Haematol. doi:10. $1111 / j .1365-2141.2011 .08771 . x$

38. Nutt SL, Heavey B, Rolink AG, Busslinger M (1999) Commitment to the B-lymphoid lineage depends on the transcription factor Pax5. Nature 401:556-562

39. Ocqueteau M, Orfao A, Garcia-Sanz R, Almeida J, Gonzalez M, San Miguel JF (1996) Expression of the CD117 antigen (c-Kit) on normal and myelomatous plasma cells. Br J Haematol 95:489-493

40. Pather S, Mohamed Z, McLeod H, Pillay K (2013) Large cell lymphoma: correlation of HIV status and prognosis with differentiation profiles assessed by immunophenotyping. Pathol Oncol Res: POR 19:695-705

41. Rafaniello Raviele P, Pruneri G, Maiorano E (2009) Plasmablastic lymphoma: a review. Oral Dis 15:38-45

42. Seegmiller AC, Xu Y, McKenna RW, Karandikar NJ (2007) Immunophenotypic differentiation between neoplastic plasma cells in mature B-cell lymphoma vs plasma cell myeloma. Am J Clin Pathol 127:176-181

43. Shaffer AL, Lin KI, Kuo TC, Yu X, Hurt EM, Rosenwald A, Giltnane JM, Yang L, Zhao H, Calame K, Staudt LM (2002) Blimp-1 orchestrates plasma cell differentiation by extinguishing the mature $\mathrm{B}$ cell gene expression program. Immunity 17:51-62

44. Stein H, Harris NL, Campo E (2008) Plasmablastic lymphoma. In: Swerdlow SH, Campo E, Harris NL (eds) WHO Classification of Tumours of Haematopoietic and Lymphoid Tissues. IARC, Lyon, France, pp 256-257

45. Swerdlow SH, Campo E, Harris NL (2008) WHO classification of tumours of haematopoietic and lymphoid tissues. IARC, Lyon, France

46. Taddesse-Heath L, Meloni-Ehrig A, Scheerle J, Kelly JC, Jaffe ES (2010) Plasmablastic lymphoma with MYC translocation: evidence for a common pathway in the generation of plasmablastic features. Mod Pathol 23:991-999

47. Tarte K, Zhan F, De Vos J, Klein B, Shaughnessy J Jr (2003) Gene expression profiling of plasma cells and plasmablasts: toward a better understanding of the late stages of B-cell differentiation. Blood 102: 592-600

48. Valera A, Balague O, Colomo L, Martinez A, Delabie J, TaddesseHeath L, Jaffe ES, Campo E (2010) IG/MYC rearrangements are the main cytogenetic alteration in plasmablastic lymphomas. Am J Surg Pathol 34:1686-1694

49. Van Camp B, Durie BG, Spier C, De Waele M, Van Riet I, Vela E, Frutiger Y, Richter L, Grogan TM (1990) Plasma cells in multiple myeloma express a natural killer cell-associated antigen: CD56 (NKH-1; Leu-19). Blood 76:377-382

50. Vega F, Chang CC, Medeiros LJ, Udden MM, Cho-Vega JH, Lau CC, Finch CJ, Vilchez RA, McGregor D, Jorgensen JL (2005) Plasmablastic lymphomas and plasmablastic plasma cell myelomas have nearly identical immunophenotypic profiles. Mod Pathol 18: $806-815$

51. Wang K, Wei G, Liu D (2012) CD19: a biomarker for B cell development, lymphoma diagnosis and therapy. Exp Hematol Oncol 1:36

52. Yu D, Rao S, Tsai LM, Lee SK, He Y, Sutcliffe EL, Srivastava M, Linterman M, Zheng L, Simpson N, Ellyard JI, Parish IA, Ma CS, Li QJ, Parish CR, Mackay CR, Vinuesa CG (2009) The transcriptional repressor Bcl-6 directs $\mathrm{T}$ follicular helper cell lineage commitment. Immunity 31:457-468 